Tropical Journal of Pharmaceutical Research December 2020; 19 (12): 2583-2590

ISSN: $1596-5996$ (print); 1596-9827 (electronic)

(C) Pharmacotherapy Group, Faculty of Pharmacy, University of Benin, Benin City, 300001 Nigeria.

Available online at http://www.tjpr.org

Original Research Article

http://dx.doi.org/10.4314/tjpr.v19i12.15

\title{
Phosphatidylethanolamine binding protein 1 enhances sensitivity of gastric cancer cell to 5-fluorouracil via inhibition of cell proliferation, migration and invasion
}

\author{
Mengxin Lin ${ }^{1-3}$, Xiaoyan Lin ${ }^{1-3}$, Xiaobing Huang ${ }^{1-3}$, Qing Liu ${ }^{1-3}$, Riping $\mathrm{Wu}^{1-3}$, \\ Xinli Wang ${ }^{1-3}$, Dongta Zhong ${ }^{1-3 *}$ \\ ${ }^{1}$ Department of Medical Oncology, Fujian Medical University Union Hospital, ${ }^{2}$ Fujian Key Laboratory of Translational Cancer \\ Medicine, ${ }^{3}$ Fujian Medical University Stem Cell Research Institute, Fuzhou 350001, Fujian, PR China
}

*For correspondence: Email: qvxib1@163.com

Sent for review: 14 August 2020

Revised accepted: 23 November 2020

\begin{abstract}
Purpose: To determine the association between phosphatidylethanolamine binding protein 1, which is an Raf kinase inhibitor protein (RKIP), and 5-fluorouracil (5-FU) via analysis of the association between RKIP and clinical responses in individuals treated using fluorouracil-based chemotherapy.

Methods: Human gastric cancer cell lines MGC-803 and SGC-7901 were used in this study. Cell viability was measured using 3-(4,5-dimethylthiazol-2-yl)-2,5-diphenyltetrazolium bromide (MTT) assay. Apoptosis and migration were determined with flow cytometry and Transwell chamber assays, respectively. The MRNA and protein expressions of apoptosis-related factors were assayed using realtime polymerase chain reaction (RT-PCR) and Western blotting, respectively, while the expression of RKIP was determined by immunohistochemical staining.

Results: Chemotherapeutic drug (5-FU) treatment induced low RKIP expression levels in tumorigenic GC cells, thereby sensitizing the cells to apoptosis (8.57 vs $1.25 \%, p<0.01)$. The highest RKIP level correlated well with initiation of apoptosis (4.20 vs $1.25 \%, p<0.01$ ). Following in vitro downregulation of RKIP, there was increase in the viability and proliferation of RKIP-inhibited cells over time, and these changes were linked to alterations in cell cycle phases and increased optical density in MTT proliferation assay (1.55 vs 1.18, $p<0.01)$. In vitro Transwell assay measurement revealed an association between RKIP downregulation and enhancement of cell migration potential (652 vs 436, $p<$ 0.01). Ectopic RKIP expression restored the apoptotic sensitivity of resistant cells (14.30 vs $1.36 \%, p<$ 0.01). This sensitization was annulled by upregulation of survival routes. Reduction of RKIP by expression of antisense and siRNA conferred resistance on cancer cells sensitive to 5-FU-mediated apoptosis (6.88 vs $2.13 \%, p<0.01$ ).

Conclusion: Thus, RKIP is a promising therapeutic strategy for improving the efficacy of clinically relevant chemotherapeutic drugs for GC.
\end{abstract}

Keywords: Gastric cancer, Raf kinase inhibitor protein, Cell proliferation, Invasion, Apoptosis, Chemotherapy, Phosphatidylethanolamine binding protein 1

\begin{abstract}
This is an Open Access article that uses a funding model which does not charge readers or their institutions for access and distributed under the terms of the Creative Commons Attribution License (http://creativecommons.org/licenses/by/4.0) and the Budapest Open Access Initiative (http://www.budapestopenaccessinitiative.org/read), which permit unrestricted use, distribution, and reproduction in any medium, provided the original work is properly credited.

Tropical Journal of Pharmaceutical Research is indexed by Science Citation Index (SciSearch), Scopus, International Pharmaceutical Abstract, Chemical Abstracts, Embase, Index Copernicus, EBSCO, African Index Medicus, JournalSeek, Journal Citation Reports/Science Edition, Directory of Open Access Journals (DOAJ), African Journal Online, Bioline International, Open-J-Gate and Pharmacy Abstracts
\end{abstract}

(C) 2020 The authors. This work is licensed under the Creative Commons Attribution 4.0 International License 


\section{INTRODUCTION}

Gastric cancer (GC) is the second most prevalent cancer all over the globe. China is among several Asian nations with a high incidence of GC and high level of mortality from the disease. Although the incidence and mortality associated with GC have been declining steadily, prognosis in several cases is bad due to late diagnosis and metastasis.

The Raf kinase inhibitor protein (RKIP) is a globular protein with molecular weight of 20-25 $\mathrm{kDa}$, and it belongs to the PEBP family made up of over 400 members [3]. It (RKIP) is phosphatidylethanolamine-binding protein in bovine brain. Studies have shown that RKIP usually binds to Raf-1 and blocks Raf-1-induced MEK phosphorylation [4,5]. In addition, RKIP regulates signaling routes and influences several processes in cells [6]. Moreover, RKIP exerts anti-angiogenic, anti-intravasating, antiextravasating and anti-metastatic effects on tumors $[7,8]$. However, not much is known about the molecular mechanisms involved in the RKIPinduced inhibition of tumor metastasis.

Several signaling pathways are negatively modulated by RKIP. However, the precise pathways or effectors involved have not yet been identified. Thus, the identification of the signaling pathways and elucidation of the effector genes regulated by RKIP will not only enhance knowledge of the mechanism of suppression of metastasis, but will also be beneficial for inhibition of metastasis in the clinics. In this study, based on previous findings, the effect of RKIP on malignancy of GC and sensitivity to chemotherapy were investigated. Therefore, the expressions of RKIP protein in GC cells and normal cells were assayed, and the effects of RKIP suppression on the malignancy of GC and sensitivity to chemotherapy were determined. Specifically, the study was designed to determine if there is an association between RKIP expression and clinical response in GC cases subjected to fluorouracil-based chemotherapy.

\section{EXPERIMENTAL}

\section{Cell lines, culturing and transfection}

Human GC cell lines MGC-803 and SGC-7901 were obtained from Cell Bank of Chinese Academy of Sciences. They were maintained in RPMI-1640 having $10 \%$ FBS and $1 \%$ penicillinstreptomycin at $37{ }^{\circ} \mathrm{C}$ in a $5 \% \mathrm{CO}_{2}$ humidified incubator. The culture-related chemicals were bought from Hyclone, while 5-FU was bought from Sigma-Aldrich.

\section{Overexpression plasmid and shRNA}

The RKIP shRNA targeting open reading frame of RKIP was 5'-CGAGCAGCTGTCTGGGAA GTA-3'. An unrelated 19-nt sequence (5'TTCTCCGAACGTGTCACGT-3') was used as shRNA-negative control. The coding sequence of RKIP was cloned into pcDNA3.1 plasmid by Clonetech. The negative control used was pcDNA3.1. In the overexpression process, $2 \times 10^{6}$ cells from each cell line were plated separately and cultured overnight. The serum-free medium was changed, followed by addition of siRNA or plasmid with lipofectamine 3000 (Invitrogen). After incubation for $6 \mathrm{~h}$, the medium was replaced with $10 \%$ FBS. After culturing for $48 \mathrm{~h}$, the efficiency of inhibition or overexpression was measured with RT-PCR and Western blotting.

\section{MTT assay}

In cell proliferation assay, each cell line was plated at a density of 2000 cells/well in triplicates in 96-well plates and were subjected to incubation for 2 days at $37^{\circ} \mathrm{C}$ in a $5 \% \mathrm{CO}_{2}$ humidified chamber, followed by addition of 10 $\mu \mathrm{L}$ of MTT $(10 \mathrm{mg} / \mathrm{mL})$ to each well, and incubation for $2 \mathrm{~h}$ at $37^{\circ} \mathrm{C}$. Thereafter, the MTT was discarded, and $100 \mathrm{uL}$ of dimethyl sulphoxide (Sigma) was added to every well, so as to solubilize the formazan crystals formed. The absorbance of formazan solution was read at $595 \mathrm{~nm}$ in a microplate reader (Thermo Fisher).

\section{Protein extraction and Western blot assay}

Cells and tissues were lysed in $50 \mathrm{mM}$ radioimmunoprecipitation assay buffer containing $150 \mathrm{mM}$ sodium chloride, 1\% NP-40, protease inhibitor, $0.5 \% \mathrm{Na}$ deoxycholic acid and $1 \mathrm{mM}$ PMSF. The protein content of the lysate was measured using BCA protein assay kit. Equal protein levels were separated via SDS-PAGE, and trans-blotted onto PVDF membrane using semi-dry transfer. The membrane was blocked by incubation using $5 \%$ skimmed milk for 60 min, and was thereafter incubated overnight with the following primary antibodies: RKIP (ab76582, Abcam); GAPDH (ab8245, Abcam); Bax (ab77566, Abcam); caspase-3 (ab32042, Abcam); Bcl-2 (ab32124, Abcam), and RKIP (ab76582, Abcam). Following rinsing, the membrane was treated with the $2^{\circ}$ antibodies goat anti-mouse IgG HRP (m21001) and goat anti-rabbit IgG HRP (m21002) at room temperature for $60 \mathrm{~min}$. Thereafter, ECL and Western blot detection system (GE Lifescience) were used to measure bound antibodies. 


\section{RNA extraction and RT-PCR}

Total RNA extraction was done using TRIzol reagent. First-strand complementary miRNA was produced from RNA with PrimeScript RT master Mix Perfect Real Time. The RT-PCR was done using SYBR green (Takara, Dalian, China) on Applied Biosystem Stepone Plus RT-PCR system, with GAPDH as loading control. Table 1 shows the sequences of the primers used.

\section{Flow cytometry}

Cell apoptosis was measured flow cytometrically. Samples for cell cycle were harvested via tryptic digestion and rinsed two times in PBS. After addition of Annexin V-FITC and PI in the dark, the samples were allowed to stand at laboratory temperature for $15 \mathrm{~min}$, followed with washing twice with binding buffer.

\section{Assay of cell migration}

This was carried out using a Transwell chamber membrane with $8.0 \mu \mathrm{m}$ pores in 24-well plates (Millipore). $2 \times 10^{4}$ cells in $100 \mathrm{uL}$ serum-deficit medium were seeded onto the upper part of the Transwell chamber, while the lower chamber contained $1 \mathrm{~mL} 10 \%$ FBS medium. After culturing for $8 \mathrm{~h}$, the medium was discarded, and the non-migrating cells were wiped off with cotton bud, while migrative cells on the lower chamber were stained with $0.1 \%$ crystal violet.

\section{Immunohistochemistry}

Tissue sections (4- $\mu \mathrm{m}$ thick) were subjected to standard immunochemical staining procedures. The stained sections were examined (10 fields per section) for positive nuclear staining at $x 400$ amplification, followed by scoring. The \% tumorpositive cells was classified viz: $<10 \%=0 ; 10-$
$30 \%=1 ; 31-50 \%=2$, and $>50 \%=3$. Total scores of $0-1$ and $\geq 2$ were considered as negative and positive, respectively.

\section{Statistical analysis}

The results are presented as mean \pm SD. (SPSS 17.0). Statistical analysis was done using $t$-test with SPSS 17.0. Values of $p<0.05$ were assumed as indicative of significant differences.

\section{RESULTS}

\section{Downregulation of RKIP}

Table 1 shows that there was strong positive expression of RKIP in $85.0 \%(68 / 80)$ of paratumor tissue specimens, while the corresponding value in GC tissue was only $18.75 \%(15 / 80)(p<$ 0.001 ). Figure $1 \mathrm{~A}$ presents the results of staining for GC and non-GC tissues. The original data in TCGA revealed higher expression of RKIP in GC than in non-cancerous tissues (Figure $1 \mathrm{~B}$ and C). These findings suggest that RKIP might be associated with the progression of GC.

\section{RKIP inhibited cell proliferation and enhanced chemosensitivity to 5-FU}

To elucidate the role of RKIP in GC, MGC-803 and SGC-7901 cell lines were used to conduct further functional studies. In the first step, RKIP, sh-RKIP or NC was transfected into GC cells in order to unravel the gain- or loss-of-function effect on GC cell proliferation. Western blot and RT-PCR assays indicated that the transfection efficiency of RKIP increased 3 to 4 times, while the transfection efficiency of sh-RKIP decreased 2 to 3 times, when compared to control cells (Figure $2 \mathrm{~A}-\mathrm{F}$ ).

Table 1: Sequences of the primers used in the experiment

\begin{tabular}{lll}
\hline Gene & forward & Reverse \\
\hline RKIP & CAGCAGGAAGGATCCCAAATA & CACATAATCGGAGAGGACTGTG \\
Bax & GGAGCTGCAGAGGATGATTG & AGTTGAAGTTGCCGTCAGAA \\
Bcl-2 & GGAGGATTGTGGCCTTCTTT & GTTCAGGTACTCAGTCATCCAC \\
Caspase-3 & GCAGGACACCACAATGAGTA & GCCTAGATCCCTGAGCTTTG \\
GAPDH & GGTGTGAACCATGAGAAGTATGA & GAGTCCTTCCACGATACCAAAG \\
\hline
\end{tabular}

The $2^{-\Delta \Delta C t}$ procedure was used for calculation of mRNA levels, relative to GAPDH

Table 2: RKIP expression profiles in GC and para-carcinoma tissues

\begin{tabular}{lccccc}
\hline \multirow{2}{*}{ Tissue } & \multicolumn{5}{c}{ Staining category } \\
\cline { 2 - 6 } & $\mathbf{0}$ & $\mathbf{1 +}$ & $\mathbf{2 +}$ & $\mathbf{3 +}$ & $\boldsymbol{P}$-value \\
\hline Gastric cancer $(\mathrm{n}=80)$ & $40(50)$ & $25(31.25)$ & $15(18.75)$ & $0(0)$ & $<0.001$ \\
Para-carcinoma $(\mathrm{n}=80)$ & $6(7.50)$ & $6(7.50)$ & $46(57.50)$ & $22(27.50)$ & \\
\hline
\end{tabular}

Values are presented as number $(\%)$ 


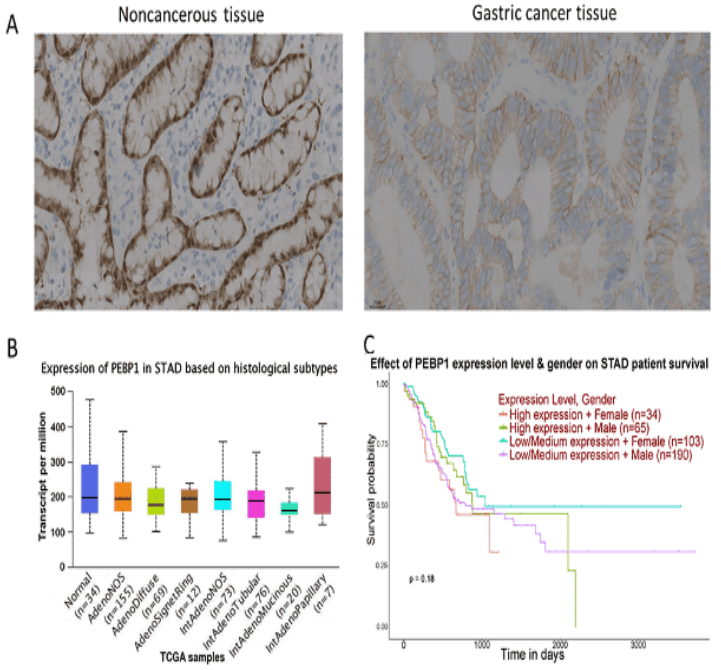

Figure 1: Representative expression profiles of RKIP in GC tissues. (A) Immunohistochemical staining of RKIP in gastric cancer tissues and surrounding noncancerous tissue samples. Scale bar $=20 \mu \mathrm{m}$. (B) RNA expression levels of RKIP gene in STAD. (C) Kaplan-Meier curves for overall survival, as stratified with RKIP expression in STAD

To determine the influence of RKIP on the malignant behavior of the GC cell lines, in vitro motility assays were carried out. Results from MTT assay indicated that combined treatment with RKIP+5-FU markedly suppressed the proliferation of the two cell lines, when compared with the control. This situation was reversed by shRKIP+5-FU where FU markedly suppressed the proliferative potential of the GC cells, when compared with the RKIP knockdown plasmid (Figure $3 \mathrm{~A}-\mathrm{D}$ ). Thus, RKIP blocked the proliferation of the GC cells and enhanced their sensitivity to 5 -FU.

\section{A combination of RKIP and 5-FU promote apoptosis of GC cells}

Based on the results of MTT assay, flow cytometry was used to assess the apoptotic influence of RKIP on GC cell lines. Double staining of infected MGC-803 cells with Annexin V-FITC and $\mathrm{PI}$ showed obvious increases in apoptosis in RKIP-overexpressing cells, when compared with control cells, while transfection with RKIP inhibitor decreased the population of apoptotic MGC-803 cells. When 5-FU was added, there was an enhancement in proportion apoptotic cells, relative to non-chemotherapy drug group. Thus, RKIP promoted apoptosis GC cell line MGC-803, and enhanced the sensitivity of the cells to 5-FU (Figure $4 \mathrm{~A}$ and $\mathrm{B}$ ). Similar results were obtained with SGC-7901 cell line (Figure $5 \mathrm{~A}$ and $\mathrm{B}$ ).

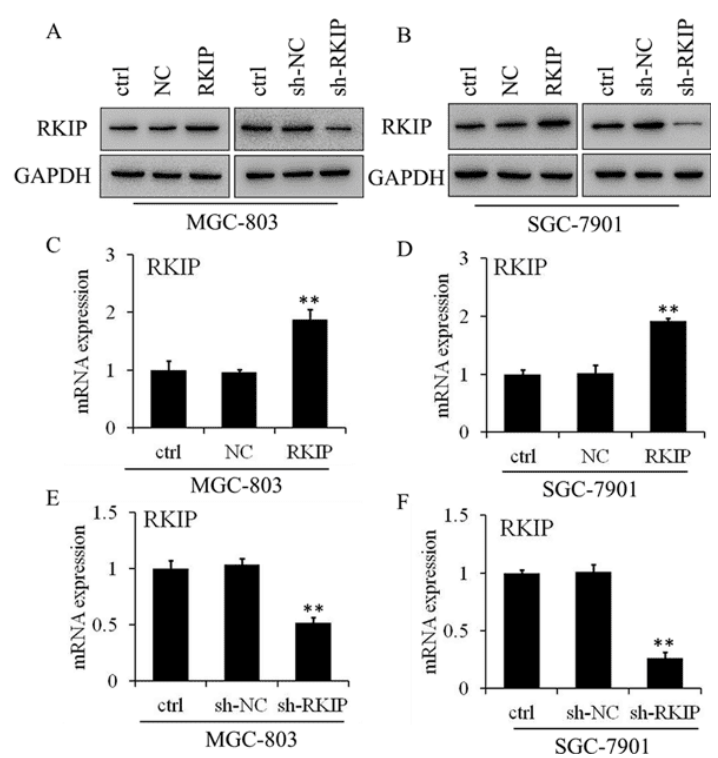

Figure 2: Efficacy of RKIP knockdown or overexpression by lentivirus. Western blotting analysis of efficiency of RKIP knockdown or overexpression by lentivirus in the GC cells (A and B). Efficiency of RKIP knockdown or overexpression by lentivirus in MGC803 and SGC-7901 cell lines (C-F). ctrl: control; LVNC: negative control; LV-RKIP: overexpression. ${ }^{* *} P<$ 0.01 , compared to LV-NC.

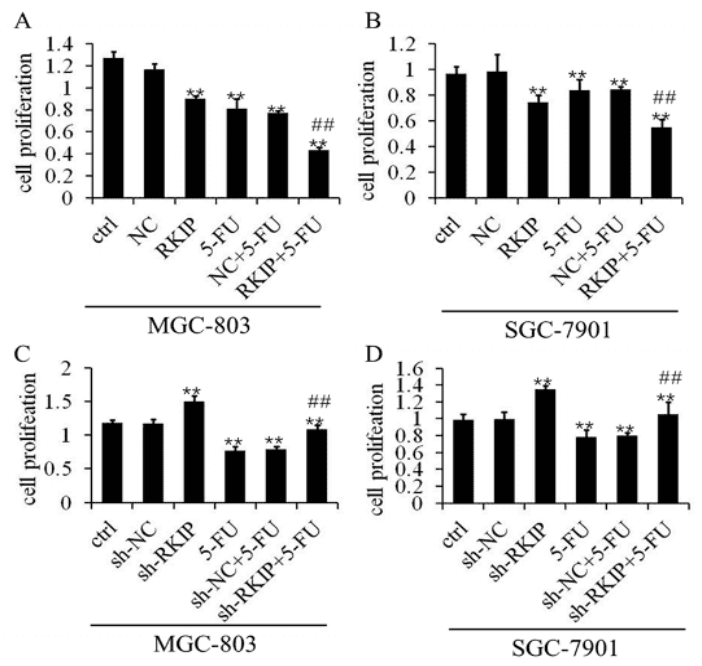

Figure 3: RKIP inhibited cell proliferation and enhanced sensitivity to 5-FU. (A) Upregulation of RKIP inhibited the proliferation of GC cell line MGC-803 when treated with 5-FU. The proliferation curves were obtained from MTT assay using absorbance readings at $592 \mathrm{~nm}$. (ctrl: control; LV-NC: negative control; LVRKIP overexpression). ${ }^{* *} P<0.01$, vs LV-NC, \#\# $P<$ 0.01 , compared to NC+5-FU). (B) Downregulation of RKIP promoted proliferation of MGC-803 cells when exposed to 5-FU. (C) Upregulation of RKIP inhibited the proliferative capacity of GC cell line SGC-7901 when exposed to 5-FU. (D) Downregulation of RKIP promoted the proliferation of SGC-7901 cells when exposed to 5-FU 
A

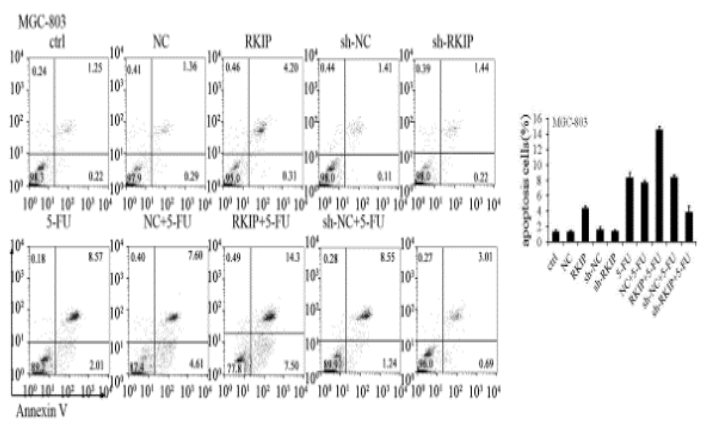

Figure 4: Combination of RKIP and 5-FU promoted apoptosis of GC cells. (A-B) Flow cytometric results of percentage apoptosis in MGC-803 cells. (ctrl: control; LV-NC: negative control; LV-RKIP overexpression). ${ }^{*} P<0.01$, vs LV-NC, LV-sh-RKIP: RKIP knockdown; ${ }^{*} p<0.01$, vs LV-sh-NC. \#\# $P<0.01$, compared to $\mathrm{NC}+5-\mathrm{FU}$ or sh-NC+5-FU.

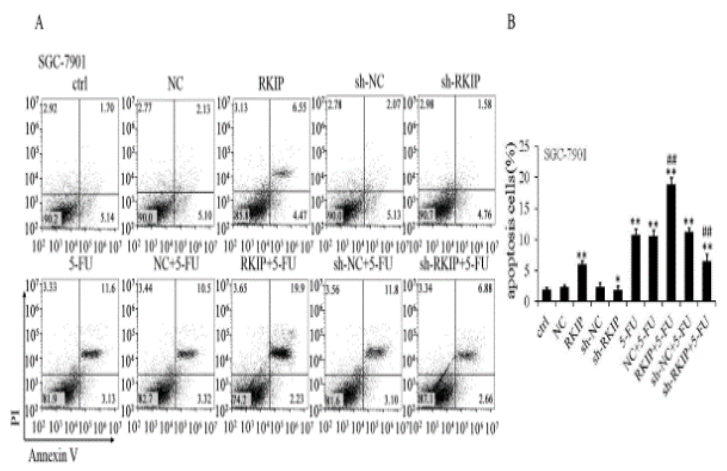

Figure 5: Combination of RKIP and 5-FU promoted apoptosis of GC cells. (A-B) Flow cytometric results of percentage apoptosis in SGC-7901 cells. (ctrl: control; LV-NC: negative control; LV-RKIP overexpression). ${ }^{\star *} P<0.01$, vs LV-NC, LV-sh-RKIP: RKIP knockdown; ${ }^{*} p<0.01$, vs LV-sh-NC. \#\# $P<0.01$, vs NC+5-FU or sh-NC+5-FU.

RKIP promoted apoptosis via regulation of apoptosis-related factors in GC

Data showed that RKIP exerted tumorsuppressing effect by regulating cell apoptosis of the GC cell lines. The protein expressions of caspase-3 and Bax were downregulated in GC cells when transfected with RKIP plasmid. On the other hand, Bcl-2 expression was increased in RKIP-overexpressing cells, and suppressed in RKIP-inhibited cells. Moreover, 5-FU consistently enhanced the protein expressions of Bax and caspase-3, while inhibiting that of Bcl-2 (Figure 6 and Figure 7). Quantitative RT-PCR (qRT-PCR) was also used to determine the mRNA profiles of $\mathrm{Bcl}-2$, caspase-3 and Bax. It was found that overexpression of RKIP inhibited Bcl-2 expression, while it promoted the protein expressions of Bax and cleaved-caspase-3 in
MGC-803 and SGC-7901 cells. The chemotherapy drug 5-FU promoted mRNA expressions of Bax and caspase-3, while it inhibited mRNA expression of Bcl-2 (Figure 8 and Figure 9).

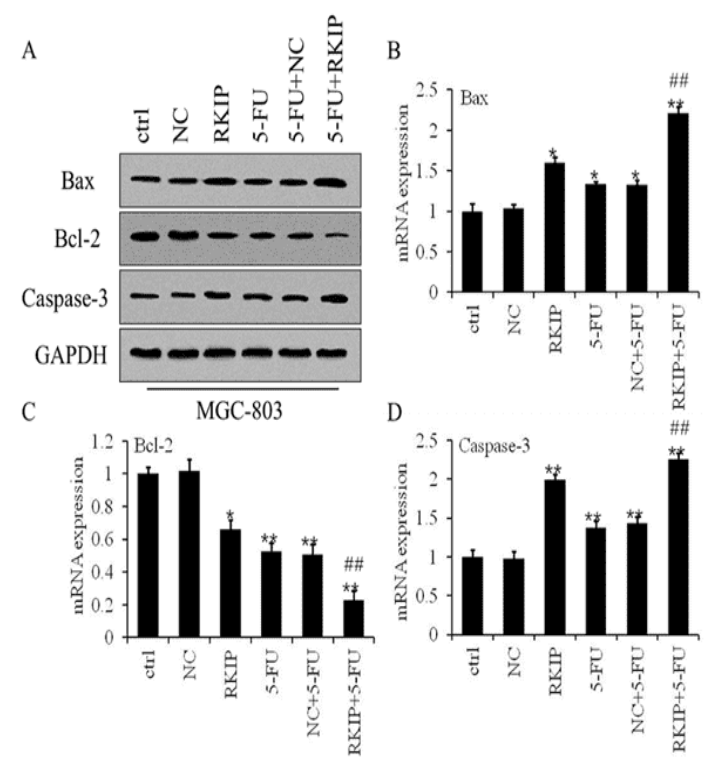

Figure 6: RKIP promoted apoptosis of GC cells through regulation of apoptosis-related factors. (A) Protein levels of apoptotic factors in MGC-803 cells, as assayed by immunoblotting. (B - D) mRNA levels of apoptotic genes in MGC-803 cells, as assayed by RTPCR

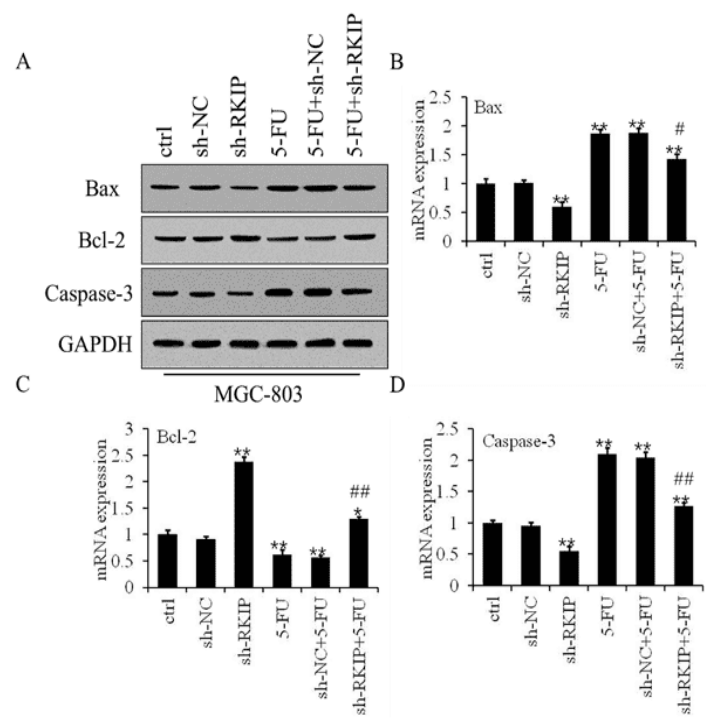

Figure 7: Downregulated RKIP inhibited apoptosis of GC cells through regulation of apoptosis-related factors. (A) Protein levels of apoptotic proteins in MGC-803 cells, as assayed with Western blotting. (B D) mRNA levels of apoptotic genes in MGC-803 cells, as assayed with RT-PCR

Trop J Pharm Res, December 2020; 19(12): 2587 


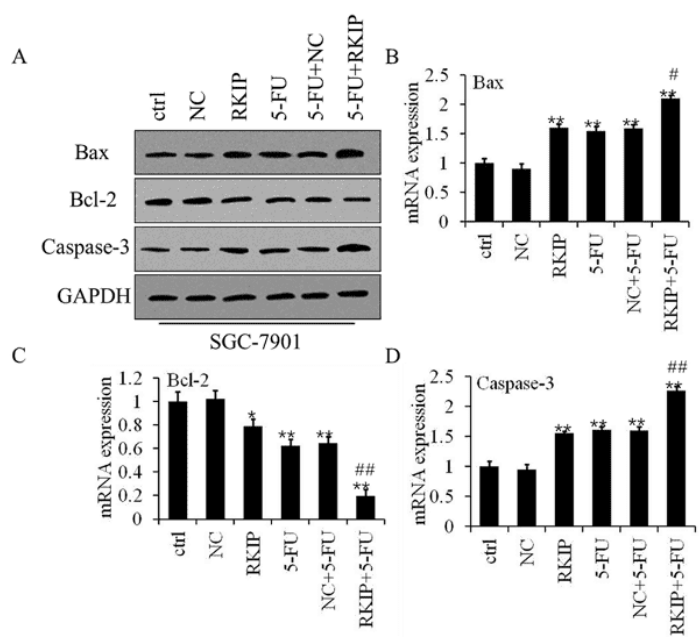

Figure 8: RKIP promoted apoptosis of GC cells through regulation of apoptosis-associated factors in SGC-7901. (A) Protein profiles of apoptotic factors in SGC-7901 cells, as assayed with immunoblotting. (BD) mRNA profiles of apoptotic genes in SGC-7901 cells, as assayed with RT-PCR

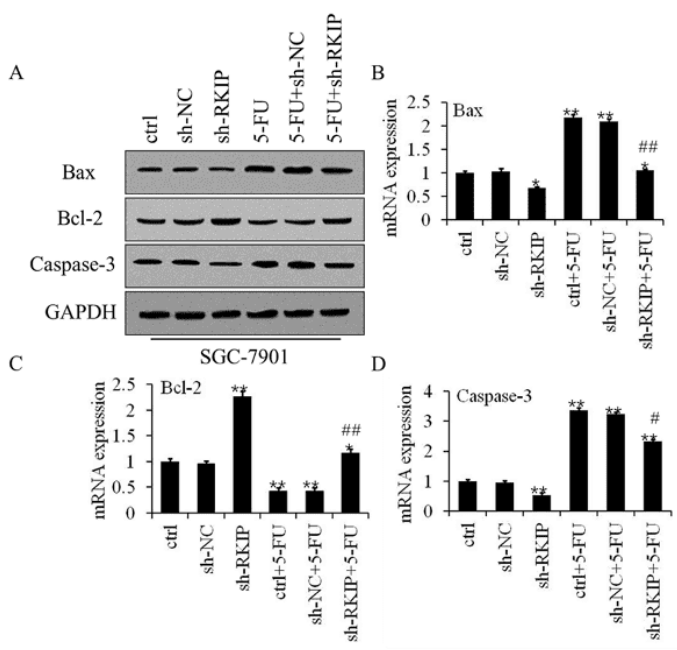

Figure 9: Downregulated RKIP inhibited apoptosis of GC cells through regulation of apoptosis-related factors in SGC-7901. (A) Protein profiles of apoptotic factors in SGC-7901 cells, as assayed with Western blotting. (B-D) mRNA expression profiles of apoptotic genes in SGC-7901 cells, as assayed with RT-PCR

\section{A combination of RKIP and 5-FU inhibited cell migration in $\mathrm{GC}$ cells}

Ectopic RKIP expression markedly inhibited chemoattractant-mediated migration of MGC-803 and SGC-7901 cells, while RKIP knockdown significantly promoted the migration of these cells. 5-Fluorouracil (5-FU) inhibited the migration of the GC cells. In the presence of 5FU, overexpression of RKIP inhibited the migration of the GC cells (Figure 10 and Figure
11). Thus, the observed anti-metastatic capacity may be due to targeted control of malignant behavior in the GC cells.
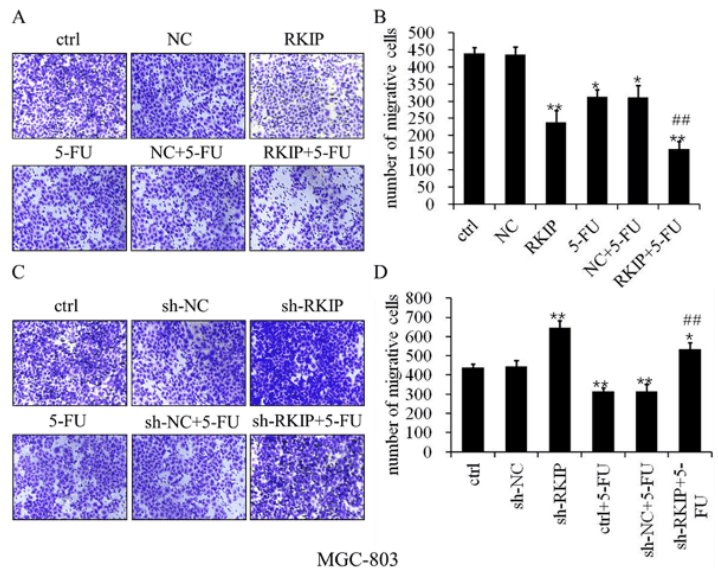

Figure 10: RKIP+5-FU suppressed migration of GC cells line MGC-803. A and B: upregulated RKIP and 5FU suppressed the migration of MGC-803 cells. $C$ and $\mathrm{D}$ : downregulated RKIP promoted the migration of MGC-803 cells. Bar graph showing populations of migrated cells in randomly-selected fields

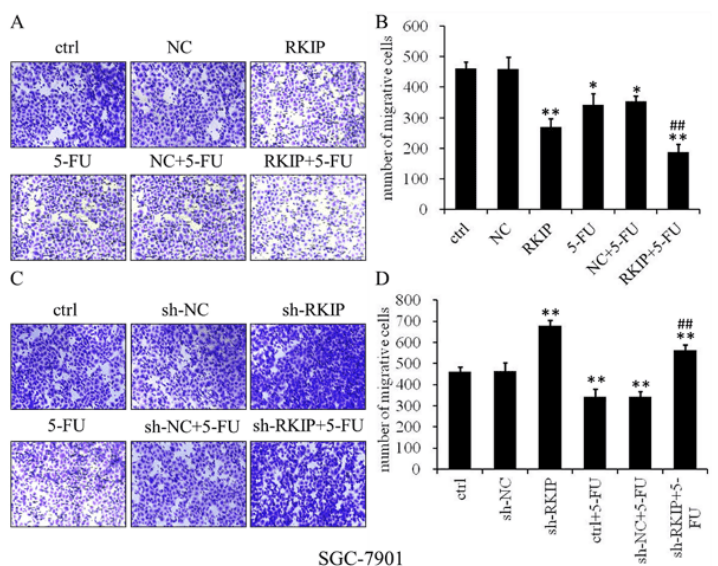

Figure 11: RKIP+5-FU suppressed migration of GC cells line SGC-7901. A and B: overexpression of RKIP and 5-FU inhibited the migration ability of SGC-7901 cells. C and D: downregulated RKIP promoted the migration ability of SGC-7901 cells. Bar graph showing populations of migrated cells in randomly-selected fields

\section{DISCUSSION}

One vital factor in the prognosis of $\mathrm{GC}$, a disease which accounts for most tumor-associated deaths, is metastatic change in the lymph node. Studies have established that RKIP inhibits metastasis in many types of cancer [12-14]. In this study, the levels of RKIP were directly correlated with cellular tumorigenicity and susceptibility to apoptosis. The MGC-803 and 
SGC-7901 cells exert tumorigenicity in nude mice, and they express limited amounts of RKIP, but this may be markedly upregulated with chemotherapy. It has been suggested that sensitization may result from enhancement of death signal pathway [15-17]. On the other hand, RKIP may render tumor cells susceptible to apoptotic changes via suppression of their proliferation, migration and invasion. It is not clear if the sensitization effect of RKIP on proliferation or apoptosis is specific to GC cells.

The results from studies on GC cell lines MGC803 and SGC-7901 revealed low RKIP concentrations which were not significantly affected when the cells were exposed to DNA impairment. Consistent with the apoptosisinducing effect of RKIP, there was low level of apoptosis following 2 days of exposure to DNAimpairing drugs at doses that induced aggravated apoptotic changes in MGC-803 cells. However, the anti-tumor agent 5-FU induced apoptosis in MGC-803 and SGC-7901. Therefore, these results are in agreement with the view that RKIP is involved in apoptosis, and they suggest that the expression of RKIP is probably controlled via multiple routes following exposure to apoptotic agents. Moreover, it was shown that normalization of RKIP concentrations in GC cell lines triggered cell proliferation, migration and apoptosis.

This study has demonstrated that RKIP inhibited cell colony formation and invasion of GC cells. These results suggest that downregulation of RKIP might promote the conversion of a normal cell to a tumor cell. Consistent with results from in vitro studies on the GC cell lines, it was also shown that the expressions of RKIP were downregulated in the GC cells, when compared with normal cells. These findings are consistent with those obtained recently in a study which identified RKIP as a new and medically-important inhibitor of metastasis in prostate carcinoma. The results of the present study suggest that cancer cell metastasis may be suppressed using druginduced expression of RKIP, leading to enhancement of apoptosis.

In the present study, it has been demonstrated that chemotherapy-induced rapid upregulation of RKIP-triggered apoptosis in human gastric cancer cells. However, in tumor cells insensitive to DNA-damaging drugs, exposure to 5-FU did not upregulate RKIP expression. In contrast, ectopic expression of RKIP sensitized these cells to apoptotic changes, while RKIP downregulation conferred insensitivity to $5-\mathrm{FU}$ by relieving its suppressive effect on two main survival routes in tumors. These results indicate that RKIP is a new indicator of apoptosis in cancers.

\section{CONCLUSION}

These results suggest that RKIP suppresses cell proliferative as well as cell migratory and invasive capacity in GC cell lines. Thus, it may be reasonably hypothesized that RKIP may serve as an inhibitor gene in human GC. Thus, it is a new index of prognosis, and a therapeutic target for gastric cancer.

\section{DECLARATIONS}

\section{Acknowledgement}

The study was supported by the Foundation of Science and Technology Innovation Project in Fujian Province (no. 2017Y9035), Foundation of Talent Cultivation Fund in Fujian Province Health Department (no. 2017-ZQN-35), and Natural Science Foundation of Fujian Province (nos. 2018J05133 and 2019J01462).

\section{Conflict of interest}

No conflict of interest is associated with this work.

\section{Contribution of authors}

We declare that this work was done by the authors named in this article and all liabilities pertaining to claims relating to the content of this article will be borne by the authors. Dongta Zhong was involved in the conception and design of the study, manuscript revision, funding support and study supervision. Mengxin Lin contributed to design of the study as well as the experiments, data analysis and manuscript writing. Xiaoyan Lin, Xiaobing Huang, Riping Wu and Xinli Wang contributed to the design of the study and interpretation of the data. All authors read and approved the final manuscript.

\section{Open Access}

This is an Open Access article that uses a funding model which does not charge readers or their institutions for access and distributed under the terms of the Creative Commons Attribution License (http://creativecommons.org/licenses/by/ 4.0) and the Budapest Open Access Initiative (http://www.budapestopenaccessinitiative.org/rea d), which permit unrestricted use, distribution, and reproduction in any medium, provided the original work is properly credited. 


\section{REFERENCES}

1. Venerito $M$, Vasapolli $R$, Rokkas $T$, Malfertheiner $P$. Gastric cancer: epidemiology, prevention, and therapy. Helicobacter 2018; 23: 12518.

2. Yan W, Qian L, Chen J, Chen W, Shen B. Comparison of Prognostic MicroRNA Biomarkers in Blood and Tissues for Gastric Cancer. J Cancer 2016; 7(1): 95-106.

3. Noh HS, Hah YS, Zada S, Ha JH, Sim G, Hwang JS, Lai $T H$, Nguyen HQ, Park JY, Kim HJ, et al. PEBP, a RAF kinase inhibitory protein, negatively regulates starvationinduced autophagy by direct interaction with LC3. Autophagy 2016; 12(11): 2183-2196.

4. Escara-Wilke J, Yeung $K$, Keller ET. Raf kinase inhibitor protein (RKIP) in cancer. Cancer Metastasis Rev 2012; 31(3-4): 615-620.

5. Zuo $H$, Lin $T$, Wang $D$, Peng $R$, Wang $S$, Gao $Y, X u X$, Zhao L, Wang S, Su Z. RKIP Regulates Neural Cell Apoptosis Induced by Exposure to Microwave Radiation Partly Through the MEK/ERK/CREB Pathway. Mol Neurobiol 2015; 51(3): 1520-1529.

6. Tang H, Park S, Sun SC, Trumbly R, Ren G, Tsung E, Yeung KC. RKIP inhibits NF-kappaB in cancer cells by regulating upstream signaling components of the IkappaB kinase complex. FEBS Lett 2010; 584(4): 662668.

7. Datar I, Qiu X, Ma HZ, Yeung M, Aras S, de la Serna I, Al-Mulla F, Thiery JP, Trumbly R, Fan X, et al. RKIP regulates CCL5 expression to inhibit breast cancer invasion and metastasis by controlling macrophage infiltration. Oncotarget 2015; 6(36): 39050-39061.

8. Keller ET. Metastasis suppressor genes: a role for raf kinase inhibitor protein (RKIP). Anti-Cancer Drugs 2015; 15(7): 663-669.

9. Fallahzadeh $H$, Jalali $A$, Momayyezi M, Bazm S. Effect of Carrot Intake in the Prevention of Gastric Cancer: A Meta-Analysis. J Gastric Cancer 2015; 15(4): 256-261.
10. Smith JP, Nadella S, Osborne N. Gastrin and Gastric Cancer. Cell Mol Gastroenterol Hepatol 2017; 4(1): 75 83.

11. Zulueta A, Caretti A, Signorelli P, Ghidoni R. Resveratrol: A potential challenger against gastric cancer. World $\mathrm{J}$ Gastroenterol 2015; 21(37): 10636-10643.

12. Frankenberger $C$, Rabe $D$, Bainer $R$, Sankarasharma $D$, Chada K, Krausz T, Gilad Y, Becker L, Rosner MR. Metastasis Suppressors Regulate the Tumor Microenvironment by Blocking Recruitment of Prometastatic Tumor-Associated Macrophages. Cancer Res 2015; 75(19): 4063-4073.

13. Zaravinos A, Bonavida B, Chatzaki E, Baritaki S. RKIP: A Key Regulator in Tumor Metastasis Initiation and Resistance to Apoptosis: Therapeutic Targeting and Impact. Cancers 2018; 10(9): 1.

14. Zou Q, Wu H, Fu F, Yi W, Pei L, Zhou M. RKIP suppresses the proliferation and metastasis of breast cancer cell lines through up-regulation of miR-185 targeting HMGA2. Archives of biochemistry and biophysics 2016; 610(2): 25-32.

15. Poursaitidis I, Wang X, Crighton $T$, Labuschagne $C$, Mason D, Cramer SL, Triplett $K$, Roy R, Pardo OE, Seckl MJ, et al. Oncogene-Selective Sensitivity to Synchronous Cell Death following Modulation of the Amino Acid Nutrient Cystine. Cell Rep 2017; 18(11): 2547-2556.

16. Shin D, Kwon HY, Sohn EJ, Nam MS, Kim JH, Lee JC, Ryu SY, Park B, Kim SH. Upregulation of Death Receptor 5 and Production of Reactive Oxygen Species Mediate Sensitization of PC-3 Prostate Cancer Cells to TRAIL Induced Apoptosis by Vitisin A. Cell Physiol Biochem 2015; 36(3): 1151-1162.

17. Smith JNP, Zhang Y, Li JJ, McCabe A, Jo HJ, Maloney J, MacNamara KC. Type I IFNs drive hematopoietic stem and progenitor cell collapse via impaired proliferation and increased RIPK1-dependent cell death during shock-like ehrlichial infection. PLOS pathogens 2018; 14(8): 1007234 